Journal of Advanced Research in Fluid Mechanics and Thermal Sciences

\title{
X-Ray Fluorescence of Copper, Nickle and Zinc Nanoparticles in Motor Oil Prepared by Laser Treatment
}

\author{
Abdulhadi Kadhim ${ }^{1, *}$, Ahmed Al-Amiery ${ }^{2, *}$ \\ 1 Department of Laser and Optoelectronic Engineering, University of Technology, Baghdad, Iraq \\ 2 Center of Energy Technology and Renewable Energies, University of Technology, Baghdad, Iraq
}

\section{ARTICLE INFO ABSTRACT}

Article history:

Received 26 November 2020

Received in revised form 15 April 2021

Accepted 21 April 2021

Available online 29 May 2021

\begin{abstract}
This paper represents an attempt to link different techniques such as laser and X-ray fluorescence (XRF). Where we used the laser in preparation and used X-rays to diagnose and analyze for non-traditional samples. The experimental procedure of the LSP is done by using a convergent lens to deliver $600 \mathrm{~mJ}(1064 \mathrm{~nm})$ of energy and 10 ns laser pulse produced by Q-switched Nd:YAG laser of $1.5 \mathrm{~mm}$ spot size in diameter. Doubled distilled deionized water (DDDW) of $3 \mathrm{~mm}$ depth is used as transparent confining layer. X-Ray fluorescence technique used to analyze and determine the concentration of different nanoparticles suspended in motor oil. The results showed the accuracy in XRF measurements. the results of the motor oil analysis for $\mathrm{Cu}, \mathrm{Ni}$ and Zn were $0.1225,0.0480$ and 0.000 weight percent respectively. Maximum relative error between actual measurements and XRF measurements were $6.5 \%, 10 \%$ and 12.5 for $\mathrm{Cu}, \mathrm{Ni}$ and $\mathrm{Zn}$ nanoparticles respectively. The best percentage of suspension is 0.01 wt.\%.
\end{abstract}

Keywords:

XRF; nanoparticles; laser; motor oil

\section{Introduction}

Nanomaterials (NMs) have uniqueness and novel properties like high reaction activity due to a large specific surface area, as the size of particle decreases, surface to volume ratio increases due to great proportion of atoms will be spread on the particle surface. NMs with different diameters and shapes have been synthesized and used in huge applications [1-3]. NPs form may be crystalline or amorphous and their surfaces can behave as carriers for gases or liquid droplets. In addition to the states of matter (solid, liquid, gaseous and plasma states), NPs consider a distinct state of matter, due to their distinct properties (large surface area and size effects). NPs morphological characteristics are: flatness, sphericity, and aspect ratio [4,5]. CuO NPs have attracted most attention due to their prospective applications, for example, in conductive films and catalysis [6]. Copper NPs synthesis

\footnotetext{
* Corresponding author.

E-mail address: abdulhadi.k.judran@uotechnology.edu.iq; abdulhadikadhim5@gmail.com; abdulhadikadhim@yahoo.com

* Corresponding author.

E-mail address: dr.ahmed1975@gmail.com
}

https://doi.org/10.37934/arfmts.83.1.178185 
methods particularly have more service compared to other NPs' synthesis methods such as gold and silver because of low price of copper $[7,8]$. The surface treatment of materials represents one of the main areas in which looks a special features that the laser beam can treat. It made this technology a very distinguished compared to other sources of energy, and make it the traditional technology upon all other technology (and even modern ones) used in heat treatment process [9-11].

In 1987, Patil used pulsed ruby laser to ablate an iron solid target where the high power laser beam that was focused on the immersed target, ionized the solid target and vicinity liquid speedily and created a metastable phase of generated iron oxide, thus the plasma plume was created at the solid-liquid interface [12]. Sequence of energy transformations occur when laser radiation is absorbed by a metal surface and interacts with the lattice, these include the sequence of relaxation and excitation electrons. The diffused heat through the metal target that is induced by nanosecondpulsed laser ablation, occurs on a time range shorter than the pulse width $[13,14]$. Metal fragments with large kinetic energy are ejected from the solid surface when the laser energy interacts with the liquid-solid interface and due to the confined liquid, the ejected fragments form an ionic region in the nearby region of the liquid-solid interface (plasma plum formation) [15]. The confined plasma in the liquid has high density and high pressure thus it induces shockwave upon the target. The shockwaves passes during the liquid and create an extra and immediate pressure. The confined liquid shows numbers of features: the liquid has thermal conductivity greater than the air, the cooling is generally easier under confined liquid, the confined liquid minifies the heat affected zone and residual thermal detriments, and causes the bubble formation that facilitates bubble motion through the confined liquid [16]. Friction and wear processes, in general are related to direct physical interaction between relatively moving surfaces. These processes can be modified by the process of lubrication [17]. The purpose of lubrication is to separate the surfaces moving relative to each other with a film of a material which can be sheared with a low resistance without causing any damage to the surfaces. The term Lubrication is applied to two different situations $[18,19]$. Fluid lubrication which occurs when a thick film of some liquid or gas completely separate two solids [20-22].

$\mathrm{X}$-ray fluorescence (XRF) involves radiating the samples with primary X-rays, which stimulate the sample to emit its own characteristic X-ray which then are analyzed [1,2]. X-ray are classified according to the technique used for determining spectral wave length or, equivalently, photon energy. The first technique called wavelength dispersive X-ray analysis (WDX) while the second called energy dispersive X-ray analysis (EDX). Of the two, EDX is much more compact, while WDX offers the best spectral resolution $[23,24]$. For WDX the radiation emitted by the sample is diffracted by the lattice planes of known d-spacing in a single crystal according to Braggs law [25-27].

$\lambda=2 \mathrm{~d}_{\mathrm{hkl}} \sin \theta$

where $\lambda$ is the wavelength of radiation diffracted through an angle $\theta$ by planes in the analyzing crystal of known $d$-spacing, and $n$ is an integer.

\section{Experimental Procedure}

\subsection{Samples Preparation}

Copper, Nickle and Zinc nanoparticles with average particle size of 30nm (particle size determined by AFM) were blending carefully with motor oil (without additives) at different percentages (0.1$0.5 \%)$. The specifications of motor oil involved SAE:4OHD, Flash point:236, Viscosity at $100{ }^{\circ} \mathrm{C}$ : 15 centistock Pour point at $-9^{\circ} \mathrm{C}$. A demountable oil sample containers were manufactured from 
Teflon. The bottom window was fitted with $6 \mu \mathrm{m}$ Myler film. The samples were prepared to conducting XRF system.

\subsection{Nanoparticles Synthesis}

Copper, Zinc and Nickel nanoparticles were prepared by using laser ablation technique. pulsed laser ablation of a piece of these metals plates were placed on the bottom of quartz vessel containing $2 \mathrm{ml}$ of DDDW. The liquid depth selected was $2 \mathrm{~mm}$ above the target ( $\mathrm{Cu}, \mathrm{Zn}$ and Ni foil plates). The benefit of DDDW with a depth of $2 \mathrm{~mm}$ to confined the laser energy to the copper sample but, if the DDDW depth exceeds $2 \mathrm{~mm}$, it will reduce the laser energy that reaches the sample. Copper was irradiated by focused Nd: YAG laser of energy of $500 \mathrm{~mJ} /$ pulse and $532 \mathrm{~nm}$. The beam spot diameter at the copper surface was $1 \mathrm{~mm}$. The number of pulses applied to the copper target ranged from 50 pulses. When the laser pulse struck the metal surface immersed in liquid; it created a spark plume with a strong shockwave that propagated in all directions. the solution changed from colorless to green, brown and red colors respectively. The intensity was increased when advancing in the laser pulses showing the formation of colloidal metals nanoparticles. The laser setup of this work as shown in Figure1.

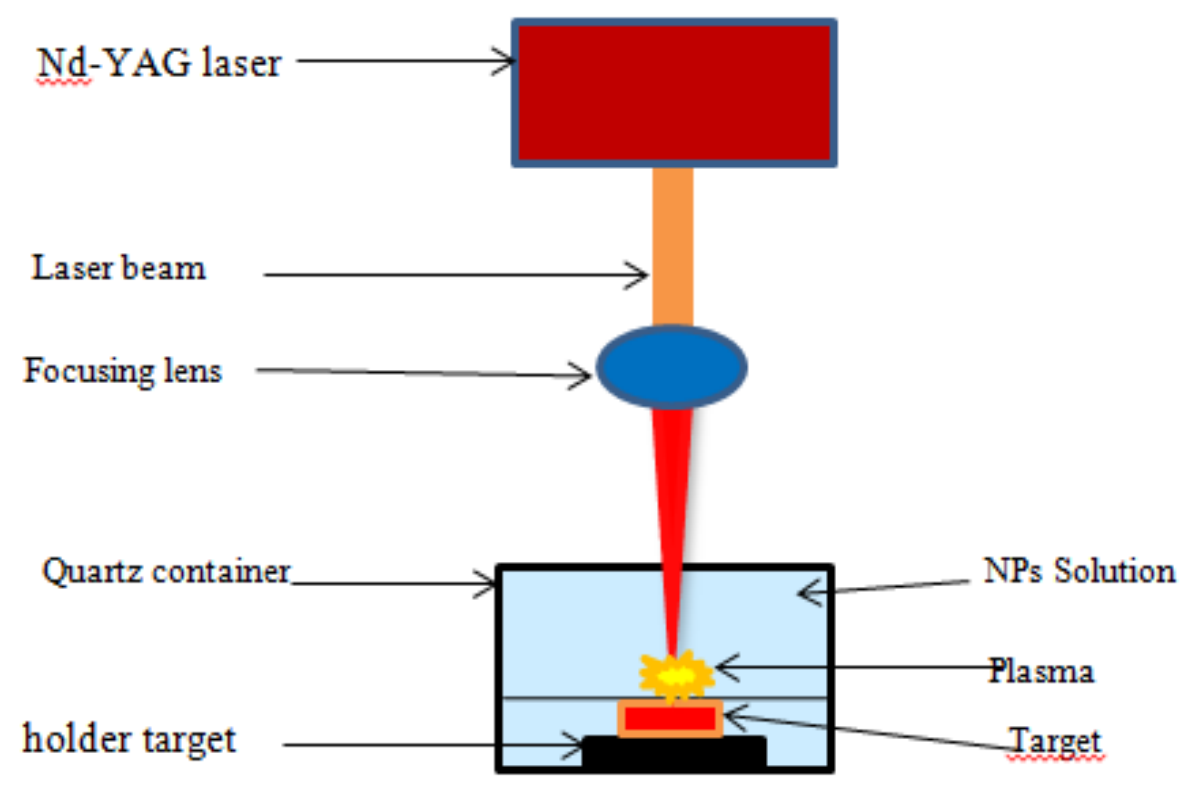

Fig. 1. Experimental setup for nanoparticles synthesis by laser ablation process

\subsection{Atomic Force Microscope Analyses}

The surface morphology of $\mathrm{Cu}, \mathrm{Zn}$ and $\mathrm{Ni}$ nanoparticles suspended prepared by laser ablation process was obtained by using atomic force microscopic images. Two drops of the suspension was deposited on glass substrate at R.T. The surface morphology, and hence particles size distribution are recognized. One NP layer deposited on the glass slice, individual colloids can be observed protruding from the slice. These nanoparticles have been imaged by an atomic force microscope operating in the contact mode in air at room temperature. Figure 2(a)-(c) reveal the 2D and 3D AFM images of metals nanoparticles suspended in oil prepared by laser ablation process. 

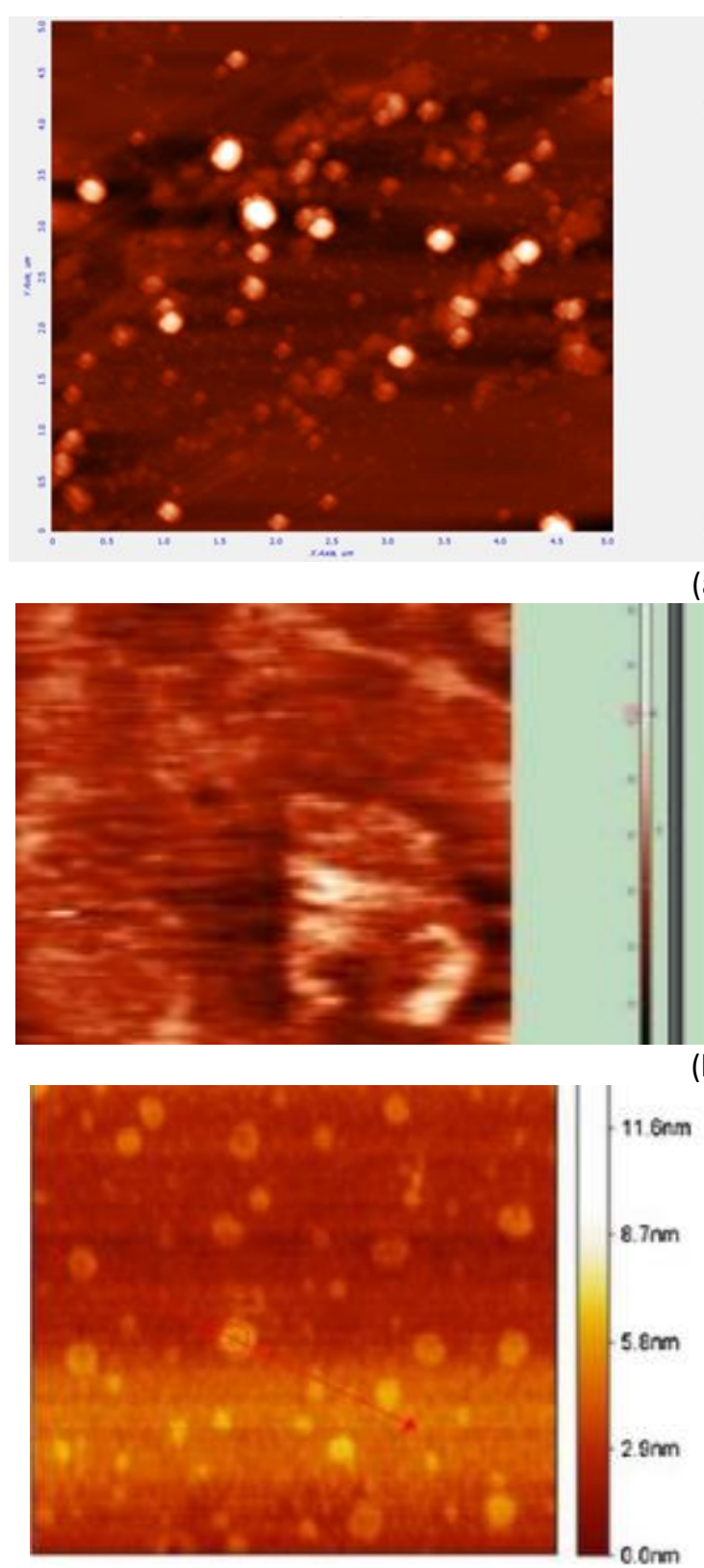

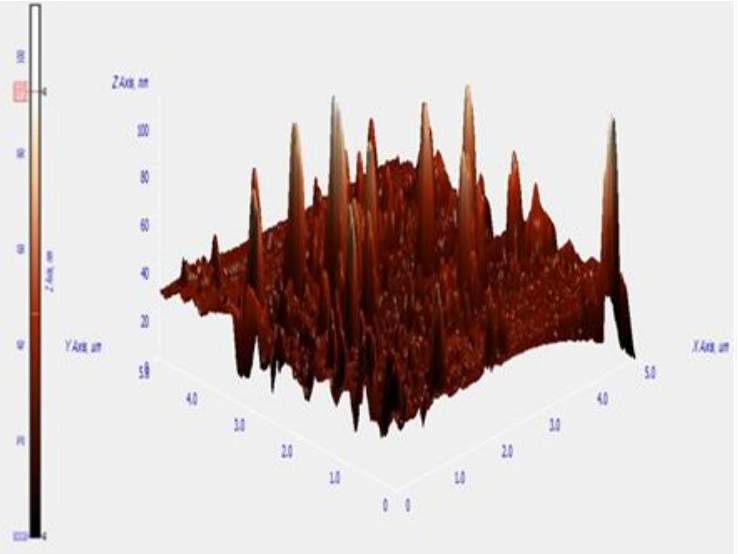

(a)

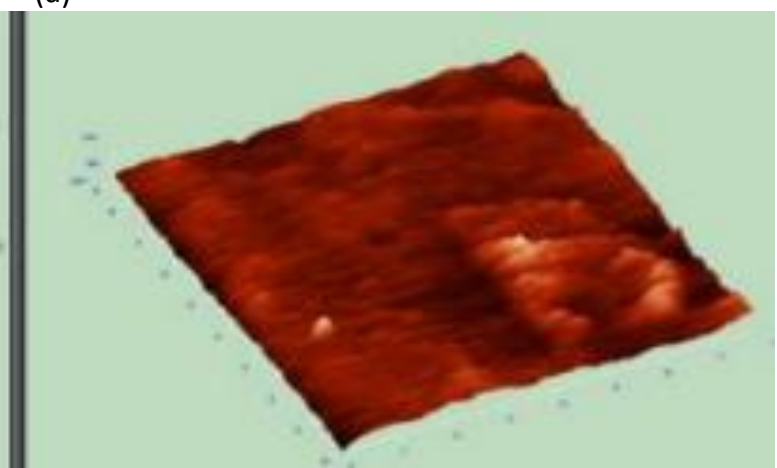

(b)

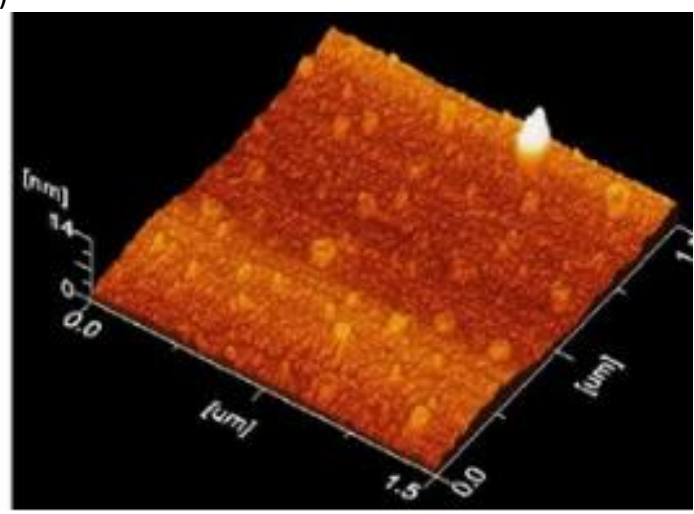

(c)

Fig. 2. (a) 2D and 3D AFM images of Cu nanoparticles suspended in oil, (b) 2D and 3D AFM images of $\mathrm{Zn}$ nanoparticles suspended in oil and (c) 2D and 3D AFM images of Ni nanoparticles suspended in oil

\subsection{X-Ray Fluorescence Measurements}

A siemens type SRS-200 sequential wavelength dispersive X-ray spectrometer was used to analyze the samples. The instrumental parameters are listed in Table 1. A molybdenum (Mo) tube target was used to obtain high detection sensitivity for copper nanoparticles suspended in oil.

Copper nanoparticles suspended in oil samples were placed in the demountable oil container to determine the samples composition by XRF - technique. The oil sample container is carefully filled with two $\mathrm{cm}^{2}$ of sample ( $\mathrm{Cu}, \mathrm{Zn}$ and $\mathrm{Ni}$ nanoparticles suspended in oil) in different concentrations and inserted in the XRF - basket at a fixed position. Counts were accumulated for 10 seconds and averaged to 1 second for all samples including $\mathrm{Cu}_{\kappa \alpha}, \mathrm{Zn} \mathrm{K}_{\alpha}$ and $\mathrm{Ni}_{\mathrm{K} \alpha}$ peaks. The statistics of counting rates were taken into account. The instrumental parameters mentioned in Table 1 were used to 
determine $\mathrm{K} \alpha$ lines intensity for nanoparticles at the diffracted angles. Also, at either sides of the peak to obtain background intensity. The net count will be change according to concentration. Counting ratios were calculated from counting rates divided by background to overcome the variations in X-ray fluorescence intensities for instabilities in the system power.

Table 1

The instrumental parameters of XRF system

\begin{tabular}{ll}
\hline Parameters & Values \\
\hline X-ray tube target & Mo \\
Power & $30 \mathrm{kv}, 17 \mathrm{~mA}$ \\
Filter & $\mathrm{Al}-$ foil \\
Atmosphere & Vac. $10^{-3}$ (m bar) in both sample and analyzing crystal \\
Sample holder diameter & $24 \mathrm{~mm}$ \\
Analyzing crystal & $\operatorname{LiF}(100)$ with $2 \mathrm{~d} 4.03^{\circ} \mathrm{A}$ \\
\hline
\end{tabular}

\section{Results and Discussion}

\subsection{Calibration Curves Results}

Samples ( $\mathrm{Cu}, \mathrm{Zn}$ and $\mathrm{Ni}$ nanoparticles suspended in oil) were examined by XRF technique. The results shows that all these nanoparticles were pure. Standard solutions of $\mathrm{Cu}, \mathrm{Zn}$ and $\mathrm{Ni}$ were prepared by dissolving known weights of these pure nanoparticles in reagent grade 2ethanol1hexanol were examined by X-ray fluorescence. A calibration curve for pure metals is prepared by plotting the ratio of $\mathrm{K} \alpha$-intensity of nanoparticles to the background versus metals nanoparticles concentration as illustrated in Figure 3.

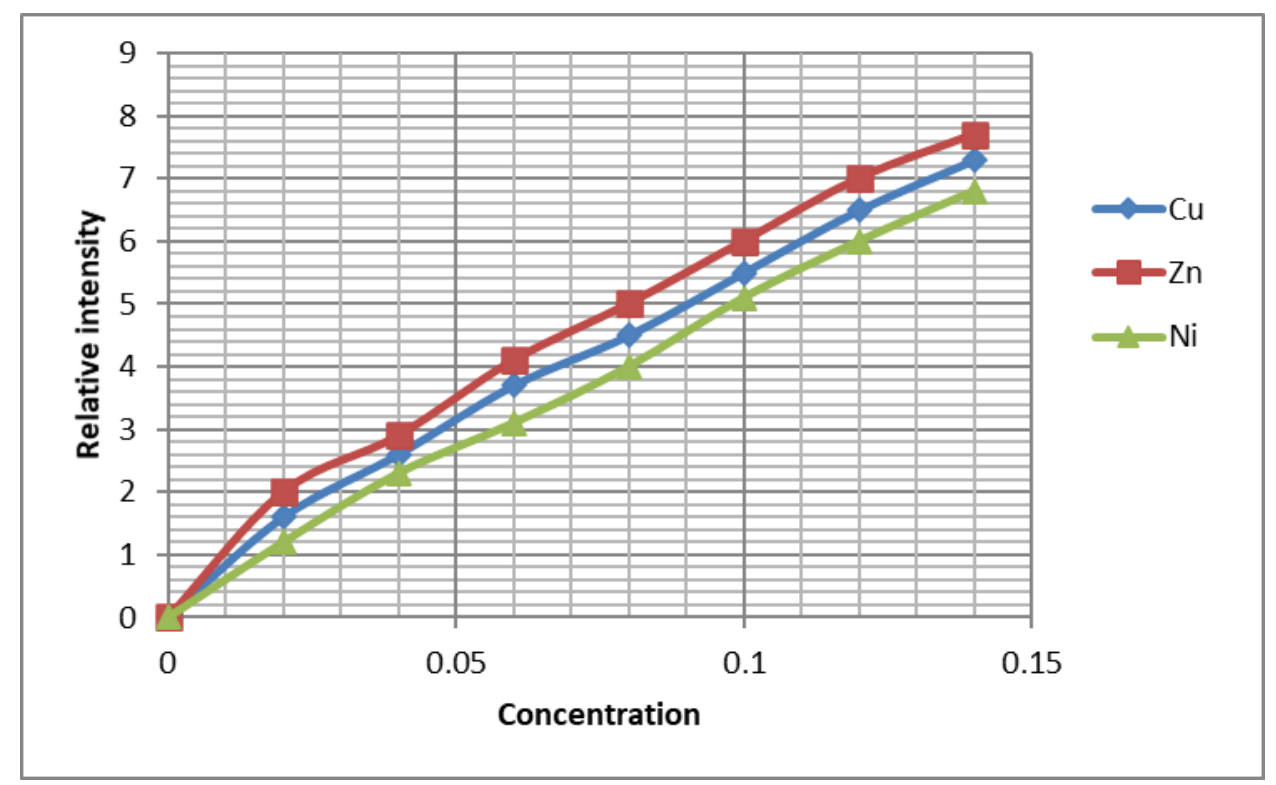

Fig. 3. Calibration curves $\mathrm{Cu}, \mathrm{Zn}$ and Ni nanoparticles in motor oil

\subsection{Motor Oil Analysis by XRF}

The elemental composition of motor oil (with and without additives) which was used in this investigation as shown in Table 2 was found by using XRF. Metals nanoparticles concentration was compared with calibration curve. Table 2 represents the elemental composition of motor oil including the ratio of $\mathrm{Cu}, \mathrm{Zn}$ and $\mathrm{Ni}$ nanoparticles. 


\section{Table 2}

Elemental composition of $\mathrm{Cu}, \mathrm{Zn}$ and $\mathrm{Ni}$ nanoparticles suspended in motor oil

\begin{tabular}{lll}
\hline Engine Oil & Elements & Concentrations (wt.\%) \\
\hline Without additives & $\mathrm{Zn}$ & 0.0920 \\
& $\mathrm{Cu}$ & 0.1225 \\
& $\mathrm{Ni}$ & 0.1020 \\
& $\mathrm{Fe}$ & 0 \\
With additives & $\mathrm{Mg}$ & 0 \\
& $\mathrm{Zn}$ & 0.229 \\
& $\mathrm{Cu}$ & 0.134 \\
& $\mathrm{Ni}$ & 0.130 \\
& $\mathrm{Fe}$ & 0.0000 \\
& $\mathrm{Mg}$ & 0.0000 \\
\hline
\end{tabular}

\subsection{XRF Results of Nanoparticles Suspended in Motor Oil}

After obtaining the results of the motor oil analysis, it was found that they contain different proportions of nickel, zinc and copper nanoparticles. Therefore, standard samples of these nanoparticles of these mineral nanoparticles were prepared with specific weight ratios and immersed in motor oil so that we can make sure of the accurate measurement of the XRF technique used for copper nanoparticle particles prepared by using laser treatment. One can be noticed through the results that the measurements of the concentrations of nanoparticles immersed in the motor oil using X-rays were very close to the actual ratios used in preparing the samples as shown in Table 3. The slight difference in measurement is due to the effect of each metal on the other, since the absorption coefficient of each element will be affected by the radiation $\mathrm{K}_{\alpha}$ emitted from the other elements this effect called matrix effect.

Table 3

XRF measurements of actual samples prepared from different nanoparticles suspended in motor oil

\begin{tabular}{llll}
\hline Nanoparticles type & Concentrations (wt.\%) & Relative error (\%) \\
\cline { 2 - 3 } & Actual measurements & XRF measurements & \\
\hline $\mathrm{Cu}$ & 0.002 & 0.00187 & 6.50 \\
& 0.004 & 0.00388 & 3.00 \\
& 0.006 & 0.00589 & 2.00 \\
& 0.008 & 0.00785 & 1.87 \\
$\mathrm{Zn}$ & 0.01 & 0.00990 & 1.00 \\
& 0.002 & 0.00175 & 12.50 \\
& 0.004 & 0.0038 & 5.00 \\
& 0.006 & 0.00581 & 3.16 \\
$\mathrm{Ni}$ & 0.008 & 0.00777 & 2.87 \\
& 0.01 & 0.0098 & 2.00 \\
& 0.002 & 0.0018 & 10.00 \\
& 0.004 & 0.00382 & 4.50 \\
& 0.006 & 0.00584 & 2.66 \\
& 0.008 & 0.0078 & 2.50 \\
& 0.01 & 0.00984 & 1.60 \\
\hline
\end{tabular}


Figure 4 shows the relative error in XRF technique measurements as a function of $\mathrm{Cu}, \mathrm{Zn}$ and $\mathrm{Ni}$ nanoparticles concentration suspended in motor oil for. The best percentage of suspension is $0.01 \mathrm{wt} \%$.

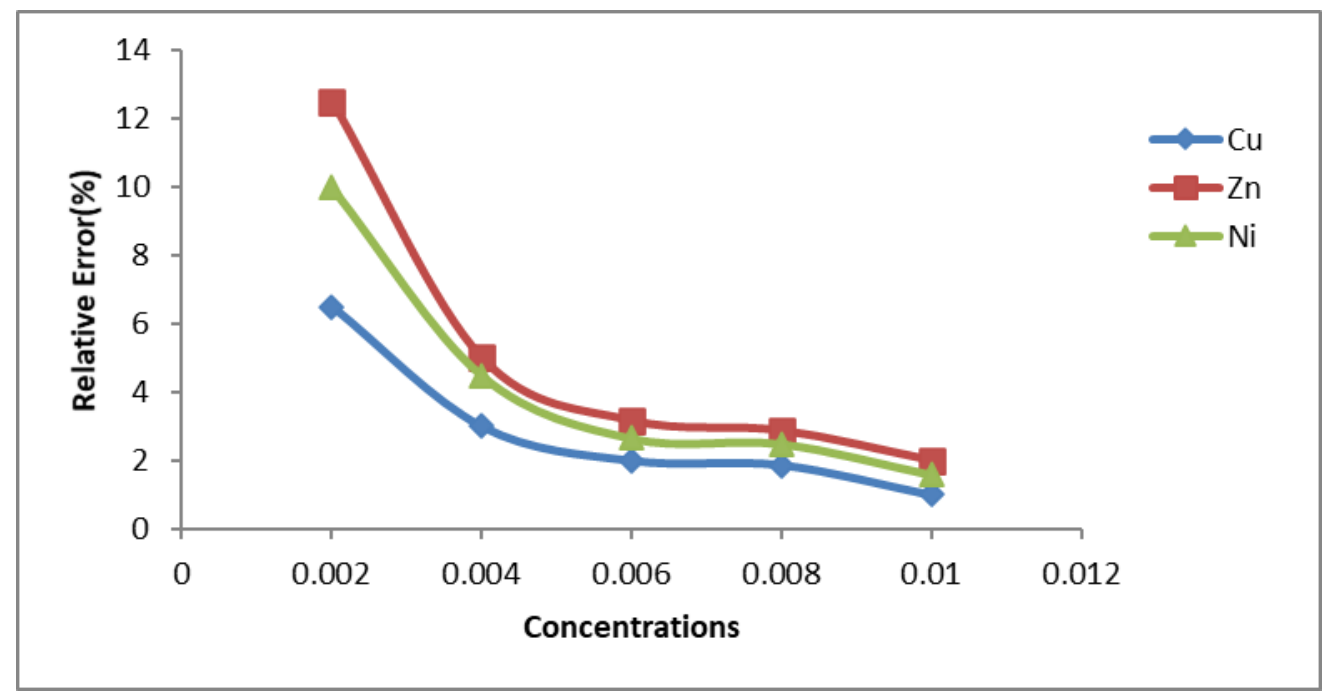

Fig. 4. The relative error in XRF measurements as a function of $\mathrm{Cu}, \mathrm{Zn}$ and $\mathrm{Ni}$ nanoparticles concentration suspended in motor oil

\section{Conclusions}

X-ray fluorescence was found to have advantages of speed and accuracy measurements and nondestructive evaluation of the qualitative and quantitative determination for metal nanoparticles in motor oils, namely $\mathrm{Cu}, \mathrm{Zn}$ and $\mathrm{Ni}$ can be performed in a few minutes for each element. We can also conclude that the sources of relative error are greater for samples with lower concentrations and this comes due to human errors as well as the effect of other elements present in the motor oil.

\section{References}

[1] Babukutty, Blessy, Fasalurahman Parakkal, and Swapna S. Nair. "Optical band gap analysis of chemically synthesized Copper nanoparticles." Journal of the American Chemical Societyvol 7: 1544-1547.

[2] Chang, Ya-Nan, Mingyi Zhang, Lin Xia, Jun Zhang, and Gengmei Xing. "The toxic effects and mechanisms of CuO and ZnO nanoparticles." Materials 5, no. 12 (2012): 2850-2871. https://doi.org/10.3390/ma5122850

[3] Kadhim, A., Ahmed A. Al-Amiery, Razi J. Alazawi, and Raid S. Jawad. "Experimental and theoretical investigation of the particle size effect on XRF intensity for some metals nanopowders in liquid media." International Journal of Research in Engineering and Innovation 1, no. 3 (2017): 193-198.

[4] Kadhim, A. "Experimental investigation for corrosion inhibition of mild steel in hydrochloric acid bath by 3-[(5phenyl-1, 3,-thiadiazol-2-yl) imino]-2-oxoindoline." Journal of Materials Science: Materials in Electronics 29, no. 6 (2018): 4683-4688. https://doi.org/10.1007/s10854-017-8420-2

[5] Mohammed, Ayad Z., and Haitham T. Hussein. "Enhancement of Surface Properties for C11000 and $6063 \mathrm{Al}$ Alloys by Using Laser Shock Wave Process." Eng. and Tech. Journal 33, no. 7 (2015): 1211-1219.

[6] Longano, D., N. Ditaranto, N. Cioffi, F. Di Niso, T. Sibillano, A. Ancona, Amalia Conte, Matteo Alessandro Del Nobile, L. Sabbatini, and L. Torsi. "Analytical characterization of laser-generated copper nanoparticles for antibacterial composite food packaging." Analytical and bioanalytical chemistry 403, no. 4 (2012): 1179-1186. https://doi.org/10.1007/s00216-011-5689-5

[7] Usman, Muhammad Sani, Nor Azowa Ibrahim, Kamyar Shameli, Norhazlin Zainuddin, and Wan Md Zin Wan Yunus. "Copper nanoparticles mediated by chitosan: synthesis and characterization via chemical methods." Molecules 17, no. 12 (2012): 14928-14936. https://doi.org/10.3390/molecules171214928

[8] Fu, Xin. "Oxidative stress induced by CuO nanoparticles (CuO NPs) to human hepatocarcinoma (HepG2) cells." Journal of Cancer Therapy 6, no. 10 (2015): 889. https://doi.org/10.4236/jct.2015.610097 
[9] Noori, Farah TM. "Optical and Structural Properties of (In2O3: ZnO: Au) Nanocomposite Thin Films Prepared by Spray Pyrolysis Method." Engineering and Technology Journal 36, no. 1 Part B (2018). https://doi.org/10.30684/etj.36.1B.9

[10] Kadhim, A., Sajed H. Alwan, and Azhar Kadhim. "Analysis of the absorption spectra in the visible and ultraviolet regions of some medical ointments available in Iraqi markets." Iraqi Journal of Physics 16, no. 36 (2018): 53-58. https://doi.org/10.30723/ijp.v16i36.27

[11] Jabbar, Malik, Farah TM Noori, and Abdulhadi Kadhim. "Synthesis, Characterization AC Electrical Properties of Cd Doped with Nano Nickel Ferrite by Sol-Gel." IOSR Journal of Applied Physics (IOSR-JAP) 8 (2016): 65-70.

[12] Li, Y., 2013. Laser ablation in liquid of Germanium in externally applied electric fields (Doctoral dissertation).

[13] Haleem, Azhar M., A. Kadhim, and Ruaa H. Abbas. "Antibacterial activity of copper oxide nanoparticles against Escherichia coli ATCC 25922 and Staphylococcus aureus ATCC 25923." Advances in Natural and Applied Sciences 11, no. 3 (2017): 1-6. https://doi.org/10.24842/1611/0017

[14] Mohammed, Dalya A., Makram A. Fakhri, and Abdulhadi Kadhim. "Reduction the Corrosion Rate of 304 Stainless Steel using Pulsed Laser Shock Penning Method." In IOP Conference Series: Materials Science and Engineering, vol. 454, no. 1, p. 012162. IOP Publishing, 2018. https://doi.org/10.1088/1757-899X/454/1/012162

[15] Kadhim, A., Azhar M. Haleem, and Ruaa H. Abass. "Anti-dermatophyte activity of Ti [O. sub. 2] NPs colloidal prepared by pulsed laser ablation in liquid environment." Advances in Environmental Biology 10, no. 12 (2016): 43 55.

[16] Hussein, Haitham T., Abdulhadi Kadhim, Ahmed A. Al-Amiery, Abdul Amir H. Kadhum, and Abu Bakar Mohamad. "Enhancement of the wear resistance and microhardness of aluminum alloy by Nd: YaG laser treatment." The Scientific World Journal 2014 (2014). https://doi.org/10.1155/2014/842062

[17] Lee, Y. K. "The use of nanofluids in domestic water heat exchanger." J. Adv. Res. Appl. Mech 3, no. 1 (2014): 9-24.

[18] Judran, Abdulhadi K. "Study of the mechanical properties of Iron-Epoxy composite materials." Iraqi Journal of Physics (IJP) 13, no. 26 (2015): 101-106. https://doi.org/10.30723/ijp.v13i26.289

[19] F.M.Rasheed. "An investigation into the dry sliding wear of some Copper alloy." MS.C Thesis submitted to technology education Dept.Technology university, 2000.

[20] Kadhim, A., Hammad R. Humud, and Lubna Abd Al Kareem. "XRD and FTIR studies for Ag/PMMA Nano composite thin films." International Journal of Computation and Applied Sciences 1, no. 2 (2016): 21-27. https://doi.org/10.24842/1611/0009

[21] Jawad, R. S., A. Kadhim, S. M. Fayadh, and T. K. Abed. "Improvement of the fatigue resistance and increase its life of specimens of naval Brass alloy using laser shock wave processing." Journal of Nanoscience and Technology (2016): 69-72.

[22] Sidik, NA Che, and O. Adnan Alawi. "Computational investigations on heat transfer enhancement using nanorefrigerants." J. Adv. Res. Des. 1, no. 1 (2014): 35-41.

[23] Donovan, John J., Donald A. Snyder, and Mark L. Rivers. "An improved interference correction for trace element analysis." In Proceedings of the Annual Meeting-Electron Microscopy Society of America, pp. 1646-1646. San francisco press, 1992. https://doi.org/10.1017/S0424820100132868

[24] Kadhim, A., Raid S. Jawad, Najwan H. Numan, and Razi J. Al-Azawi. "Determination the wear rate by using XRF technique for Kovar alloy under lubricated condition." Power 30 (2017): 17mA. https://doi.org/10.24842/1611/0016

[25] AL-Ogaili, Abdulhadi K. Judran. "Sensitivity and Lower Limit Detection Determined of XRF for Copper and Zinc Suspended in lubricated Grease." Engineering and Technology Journal 27, no. 8 (2009).

[26] Cullity, Bernard Dennis. Elements of X-ray Diffraction. Addison-Wesley Publishing, 1956.

[27] Small, J. A. "The analysis of particles at low accelerating voltages ( $\leq 10 \mathrm{kV})$ with energy dispersive $X$-ray spectroscopy (EDS)." Journal of research of the National Institute of Standards and Technology 107, no. 6 (2002): 555. https://doi.org/10.6028/jres.107.047 